\title{
The Interest in Science among Malaysian: A Comparative Study between Gender, Age Group and Ethnics
}

\author{
Mohd Arip Kasmo ${ }^{1}$, Abur Hamdi Usman ${ }^{2}$, Mohamad Mohsin Mohamad Said ${ }^{1}$, Hamdzun Haron ${ }^{1}$, Fadzilah Idris ${ }^{1}$ \\ \& Jamsari Alias ${ }^{1}$ \\ ${ }^{1}$ Centre for General Studies, The National University of Malaysia, Malaysia \\ ${ }^{2}$ Institute of Islam Hadhari, The National University of Malaysia, Malaysia \\ Correspondence: Abur Hamdi Usman, Institute of Islam Hadhari, The National University of Malaysia, Selangor, \\ 43600, Malaysia. Tel: 60-16-690-5082. E-mail: aburhamdiusman@yahoo.com
}

Received: November 28, 2014 Accepted: January 20, 2015 Online Published: April 30, 2015

doi:10.5539/ass.v11n12p174 URL: http://dx.doi.org/10.5539/ass.v11n12p174

\begin{abstract}
This paper reports a study which was conducted to know the interest in science among the Malaysian. Altogether 642 respondents from all over the country participated in the study. The respondents, male and female from different ethnics were randomly obtained. They were given booklets of questionnaire containing statements related to the issues of science. The statements were provided with responses in the form of Likert style scale ranging from 1. Strongly disagree, 2. Disagree, 3. Not sure, 4. Agree and 5. Strongly agree. The booklets were collected and the responses were analysed using the Statistical Package for the Social Sciences (SPSS) to obtain the means and percentages of the responses. The findings show that $68.3 \%$ of the respondents claimed that they have interest in science, although the interest in science is not strong, no difference of interest in science is found between male and female respondents as well as between the ethnics. However there is significant different of means between age groups.
\end{abstract}

Keywords: science, Malaysia, interest, comparative, gender, age, ethnics

\section{The Role of Science and Technology in Development: Malaysia Perspective}

The importance attached to science and technology has been reflected in several Malaysian government policies such as the Vision 2020, the $10^{\text {th }}$ Malaysian Plan, The National Science and Technology Policy, The National Biotechnology Policy and the National Agriculture Policy (Bucchi \& Trench, 2014). Various policies which have been made by the government have yet to bear fruit. The number of scientists and researchers in Malaysia is still small compared to those of the developed countries. In term of science and technology, Malaysia still lags behind the developed countries and even the New Industrial Economies (NIEs) as it was ranked 55 from the 178 in term of its performance (Mahadevan, 2007). It is well known fact that number of scientists and researchers is important factor which is crucial for achieving the status of developed nation. Therefore with the small number of scientists and researchers, the Vision 2020 which aimed at turning Malaysia into an industrial and developed nation (Sarji, 1993), is still far behind.

Science and technology play an important role in the development and progress of a nation. Science and technology is closely link to economic development of a country. Therefore many countries embarked on pursuing progress in science and technology after their independence from the colonial rulers. The Malaysian government, through the Ministry of Education introduced science to school pupil as early as year 1 at the primary education. The streaming of students to science and non-science stream begin at year 4 i.e. after the Lower Certificate of Education (LCE), in an effort to improve science and technology of the country, and then the Prime Minister of Malaysia switched the teaching instruction for science in all the government schools to English. However the step taken by the government was strongly opposed by some segment of the Malay intellectuals until finally the government decision was revoked. The issue is whether the students are interested in science or non-science subjects. A study which has been conducted in the United States found out that the students considered science profession as less creative, less people orientated compared to other career profession and difficult (Henriksen et al., 2014). 
The findings of the study in the United States was affirmed by the previous study which discovered that science education in the developed countries failed to attract the youth to study science (Chorafas, 2012). Moreover, the survey across 40 countries and discovered that science is not popular in developed countries (Csermely et al., 2007). In the developing world, there is worrying lack of interest in science (Pinto \& Couso, 2007) and in an effort to promote interest in science, certain government such as that of Singapore established the science centre which they emulated from the United States (Haren, 2010).

In Malaysia, initiative in the field of education is promoting science and technology at all levels of schooling. In early 2011, the government introduced a new curriculum including the basic knowledge on communication and information technology, a measure intended to make young people more interested in high-tech careers (Oxford Business Group, 2011). According to Hussain and Idris (2010) in the Malaysian contact, the Malaysian students at the primary level showed interest in science and they were positive about science learning but as they entered the secondary declined but not seriously.

\section{Methodological and Statistical Analysis}

The study was conducted throughout Malaysia on 642 respondents, males and females from the age of 19 to 55 years and randomly obtained. Every respondent was given a booklet containing questionnaire on the several issues of science including interest in science. The questionnaire were in the form of statements with given responses in the form of Likert style scale ranging from 1 (Strongly disagree), 2 (Disagree), 3 (Not sure), 4 (Agree), and 5 (Strongly agree). The respondents were given 30 minutes to respond to the questionnaire. After 30 minutes the booklets of questionnaire were collected and the data was analysed using the Statistical Package for the Social Sciences (SPSS) to obtain the descriptive statistic which include percentages and means. The means were also tested using the independent t-test and also one-way ANOVA.

Likert style scale was used in this study because it measures attitude of the respondents. Kothari (2011) listed five reasons why Likert scale is a good instrument of test. The five reasons are: First, it is relatively easy to construct. Second, it is more reliable instrument because respondents answer each statement included in the instrument. Third, each statement included in the Likert scale is given an empirical test for discriminating ability. Fourth, Likert scale can easily be used. Fifth, it takes less time to construct. The responses were analysed using the Statistical Package for the Social Sciences (SPSS), to find the percentages, the means, the correlation and the difference of means.

The first analysis was to obtain the mean response to the statement "I am interested in science". The result of the analysis is shown in Table 1.

Table 1. The mean response to the statement "I am interested in science"

\begin{tabular}{llllll}
\hline & $\mathrm{N}$ & Minimum & Maximum & Mean & Std. Deviation \\
\hline & 642 & 1.00 & 5.00 & 3.7710 & 1.00493 \\
Valid N & 642 & & & & \\
\hline
\end{tabular}

Table 1 shows that the mean response is 3.7710. The mean lies between 3 (not sure) and 4 (agree). The next analysis is to obtain the percentage of the response. The mean is not strong indication that the respondents have interest in science. Table 2 shows the result of the analysis.

Table 2. The percentage of the response to statement "I am interested in science"

\begin{tabular}{lllll}
\hline & Frequency & Percent & Valid Percent & Cumulative Percent \\
\hline Strongly disagree & 17 & 1.3 & 2.6 & 2.6 \\
disagree & 63 & 4.9 & 9.8 & 12.5 \\
Not sure & 123 & 9.5 & 19.2 & 31.6 \\
Agree & 286 & 22.2 & 44.5 & 76.2 \\
Strongly agree & 153 & 11.9 & 23.8 & 100.0 \\
\hline
\end{tabular}

Table 2 shows that $2.6 \%$ of the respondent strongly disagree to the statement "I am interested in science", $9.8 \%$ disagree, $19.2 \%$ not sure, $44.5 \%$ agree and $23.8 \%$ strongly agree. In total $12.4 \%$ (combination of response 1 and 2) do not accept the statement and $68.3 \%$ (combination of response 4 and 5) accepted the statement and 19.2\% are not sure. The percentages of the response are plotted to form the bar chart, as shown in Figure 1. 


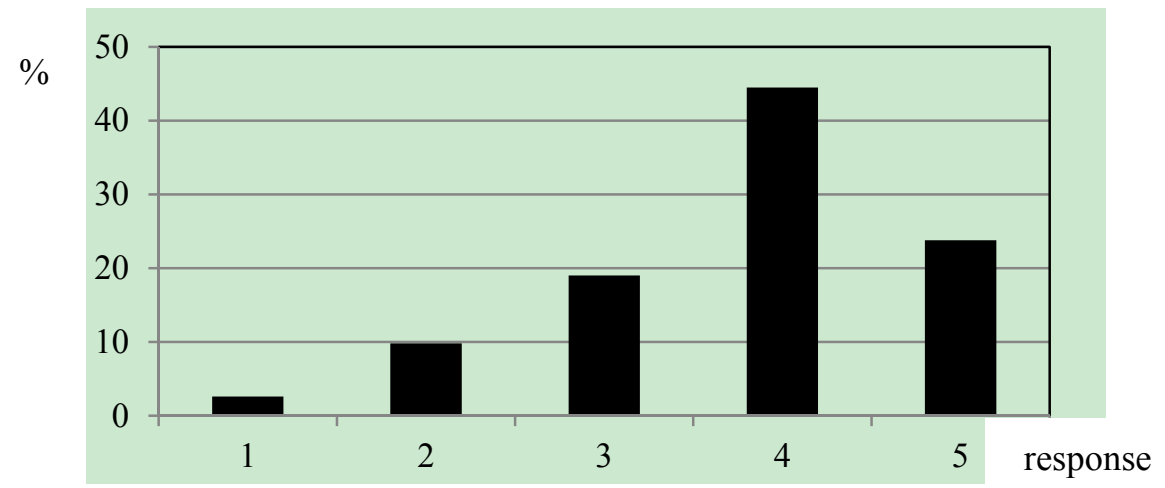

Figure 1. The bar chart of the percentage of the response of all the respondents

Figure 1 shows that the highest percentage of the response is the response no 4 which is "Agree". The next analysis is to obtain the percentages of the responses based on the ethnic of the respondents. The result of the analysis is shown in Table 3.

Table 3. The percentages of the responses based on the ethnics

\begin{tabular}{ccccccccccc}
\hline & \multicolumn{2}{c}{ Malay } & \multicolumn{2}{c}{ Chinese } & \multicolumn{2}{c}{ Indian } & \multicolumn{2}{c}{ Native of Sabah } & \multicolumn{2}{c}{ Native of Sarawak } \\
\hline & Freq & $\%$ & Freq & $\%$ & Freq & $\%$ & Freq & $\%$ & Freq & $\%$ \\
Strongly disagree & 12 & 2.7 & 2 & 1.7 & 2 & 3.6 & 1 & 4.8 & 0 & 0 \\
Disagree & 34 & 7.8 & 18 & 14.9 & 10 & 17.9 & 1 & 4.8 & 0 & 0 \\
Not sure & 85 & 19.5 & 24 & 19.8 & 7 & 12.5 & 5 & 23.8 & 1 & 25.0 \\
Agree & 194 & 44.4 & 51 & 42.1 & 27 & 48.2 & 11 & 52.4 & 1 & 25.0 \\
Strongly agree & 112 & 25.6 & 26 & 21.5 & 10 & 17.9 & 3 & 14.3 & 2 & 50.0 \\
\hline & 437 & 100 & 121 & 100 & 56 & 100 & 21 & 100 & 4 & 100 \\
\hline
\end{tabular}

Table 3 shows the percentages of the responses based on the ethnics of the respondents. The number of respondents for the native of Sabah and the Native of Sarawak are small; hence these ethnics are left aside. The percentages of the Malay respondents who rejected the statement (combination of response 1 and 2) are 10.5\%, the respondents who were neutral are $19.5 \%$ and those who accepted the statement (combination of response 4 and 5) are $80 \%$. The percentage of the Chinese respondents who rejected the statement (combination of response 1 and 2) are $16.6 \%$, those who were neutral is $19.8 \%$ and those who accepted the statement (combination of response 4 and 5) are $63.6 \%$, the percentage of the Indian respondents who rejected the statement (combination of response 1 and 2) are $21.5 \%$, those who were neutral is $12.5 \%$ and those who accepted the statement (combination of response 4 and 5) are $66.1 \%$. The percentages of the responses of the three ethnics are plotted into line graph as shown in Figure 2.

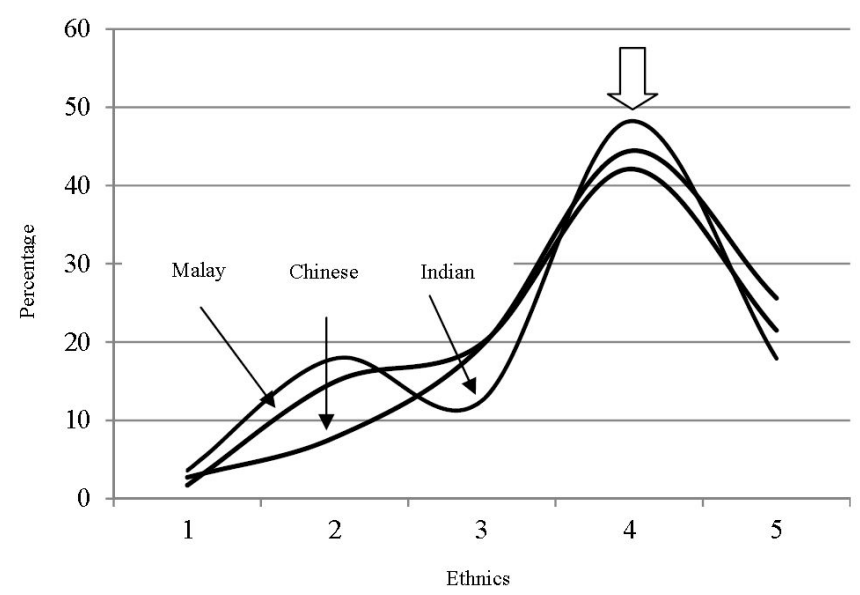

Figure 2. The line graph of percentages of the responses of Malay, Chinese and Indian ethnics 
Figure 2 shows that the most popular response is concentrated at the response number 4 (agree) for all the three main ethnics i.e. the Malays, the Chinese and the Indians. It seems that there is not much difference between the three main ethnics in term of their interest in science. The next analysis is to obtain the mean response based on the ethnics of the respondents. The next analysis is to obtain the responses according to the ethnic of the respondents. The mean responses of the respondents based on their ethnic are shown in Table 4.

Table 4. The means response according to the ethnic of the respondent

\begin{tabular}{cccc}
\hline Ethnic & Mean & $\mathrm{N}$ & Std. Deviation \\
\hline Malay & 3.8219 & 438 & .98978 \\
Chinese & 3.6694 & 121 & 1.02785 \\
Indian & 3.5893 & 56 & 1.09173 \\
Native of Sabah & 3.6667 & 21 & .96609 \\
Native of Sarawak & 4.2500 & 4 & .95743 \\
\hline
\end{tabular}

Table 4 shows that the means responses of the respondents based on their ethnic are very close to each other. The mean response for the Malay respondents is 3.8219, the mean response of the Chinese respondents is 3.6694, the mean response of the Indian respondents is 3.5893, the mean response of the Sabah is 3.6667 and the mean response of the Native of Sarawak is 4.2500. The mean difference are tested with one-way ANOVA to see if there is significant different between the mean. The result of the test is shown in Table 5 .

Table 5. One-way ANOVA test for the means response of the respondents according to ethnic

\begin{tabular}{cccccc}
\hline & Sum of Squares & df & Mean Square & $\mathrm{f}$ & Sig. \\
\hline Between Groups & 5.484 & 5 & 1.097 & 1.087 & .366 \\
Within Groups & 641.857 & 636 & 1.009 & & \\
\hline
\end{tabular}

Table 5 shows that the $p$ value is 0.366 which is bigger than the critical value of 0.05 , indicating that the difference of mean between the responses of the respondents according to their ethnics is not significant. This means that there is no difference of interest in science between the main ethnics group in Malaysia. The next analysis is to obtain the percentages of the responses based on the gender of the respondents. The result of the analysis is shown in Table 6.

Table 6. The percentage of responses based on the gender of the respondents

\begin{tabular}{ccccc}
\hline & & Male & \multicolumn{2}{c}{ Female } \\
\hline & Freq & $\%$ & Freq & $\%$ \\
\hline Strongly disagree & 9 & 3.1 & 8 & 2.3 \\
Disagree & 24 & 8.2 & 39 & 11.2 \\
Not sure & 68 & 23.2 & 54 & 15.5 \\
Agree & 124 & 42.3 & 16 & 46.6 \\
Strongly agree & 68 & 23.2 & 85 & 24.4 \\
\hline
\end{tabular}

Table 6 shows that $11.3 \%$ (combination of response 1 and 2) of the male respondents rejected the statement, $23.2 \%$ neutral and $65.5 \%$ (combination of response 4 and 5) accepted the statement. The table also shows that $23.5 \%$ (combination of response 4 and 5) of the female respondents rejected the statement, 15.5\% neutral and $71.0 \%$ (combination of response 4 and 5) accepted the statement. It seems that more female respondents accepted the statement 'I am interested in science'. The next analysis is to obtain the mean response of the respondents based on the gender and the result of the analysis is shown in Table 7.

Table 7. The mean responses of the respondents based on the gender

\begin{tabular}{cccc}
\hline Gender & Mean & $\mathrm{N}$ & Std. Deviation \\
\hline Male & 3.7415 & 294 & 1.00231 \\
Female & 3.7960 & 348 & 1.00791 \\
\hline
\end{tabular}


Table 7 shows that the mean response of the male respondent is 3.7415 while the mean response for the female respondents is 3.7960. there is very little difference of mean between the male responses and the female responses with female interest is slightly more than the male. The mean response is tested to see if the difference of mean is significant or not. The result of the test is sown in Table 8.

Table 8 . The t-test between the genders

\begin{tabular}{|c|c|c|c|c|}
\hline & \multicolumn{4}{|c|}{ Levene's Test for Equality of Variances } \\
\hline & $\mathrm{F}$ & Sig. & df & Sig. (2-tailed) \\
\hline Equal variances assumed & .201 & $.654-.684$ & 640 & .494 \\
\hline Equal variances not assumed & & -.684 & 23.331 & .494 \\
\hline
\end{tabular}

Table 8 shows that the $p$ value is 0.494 which is smaller than the critical value of 0.05 . This implies that the difference of mean of the respondent base on the gender is not significant. The next analysis is to obtain the percentage of the response based on the age of the respondents. The result of the analysis is shown in Table 9.

Table 9. Percentages of responses based on the age groups of the respondents

\begin{tabular}{ccccccc}
\hline & \multicolumn{2}{c}{$20-30$} & $31-55$ & \multicolumn{3}{c}{$>55$} \\
\hline Strong disagree & 11 & 2.4 & 5 & 3.6 & 1 & 3.6 \\
Disagree & 34 & 7.3 & 19 & 13.6 & 8 & 28.6 \\
Not sure & 83 & 17.7 & 30 & 21.4 & 8 & 28.6 \\
Agree & 213 & 45.5 & 62 & 44.3 & 8 & 28.6 \\
Strongly agree & 126 & 26.9 & 24 & 17.1 & 3 & 10.7 \\
\hline & 468 & 100 & 140 & 100 & 28 & 100 \\
\hline
\end{tabular}

Table 9 shows that the percentages of responses based on the age groups. The percentage of the respondents who rejected the statement (combination of response 1 and 2) for the age group 20-30 is 9.7\%, those who were neutral is $17.7 \%$ and those who accepted the statements is $72.4 \%$, for the age group between $31-55$, the percentage of the respondents who rejected the statement is $17.2 \%$ (combination of response 1 and 2), those who were neutral is $21.4 \%$ and those who accepted the statement is $61.4 \%$ (combination of response 4 and 5), and the percentages of the responses of the respondents for the age group more than 55 years who rejected the statement is $32.2 \%$, neutral is $28.6 \%$ and those who accepted it is $39.3 \%$ (combination of response 4 and 5 ). The percentages of the responses based on the age groups are shown in Figure 3.

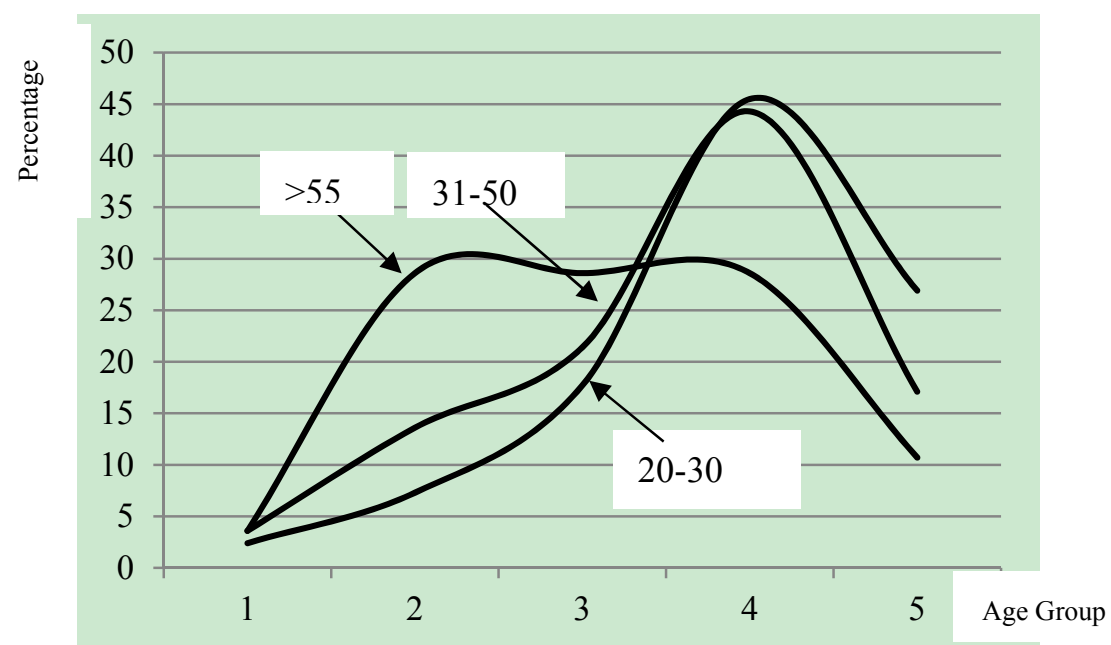

Figure 3. The line graph of the percentages of the responses based on the age groups of respondents

Figure 3 shows the line graph of the percentages of the responses based on the age group of the respondents. The line for the age group 20-30 seems to be similar but the line for the age group of more than 55 years is different from the rests. 
The next analysis is to obtain the mean according to the age group. The mean response according to the age group is shown in Table 10 .

Table 10. The mean response according to the age group

\begin{tabular}{cccc}
\hline Age groups & Mean & $\mathrm{N}$ & Std. Deviation \\
\hline $20-30$ & 3.8739 & 468 & .96797 \\
$31-55$ & 3.5786 & 140 & 1.03928 \\
$>55$ & 3.1429 & 28 & 1.07890 \\
\hline Total & 3.7767 & 636 & 1.00416 \\
\hline
\end{tabular}

Table 10 shows the mean response according to the age group. The mean response for the age group between 20 to 30 years old is 3.8739 , for the age group between 31 to 55 years old is 3.5786 and the mean response for the age group above 55 years is 3.1429 . Although the mean for the age group which is 3.7767 , which lies between 3 (not sure) and 4 (agree) is not strong acceptance to the statement "I am interested in science", nevertheless the means seem to show that the interest in science decreases with the age as shown in Figure 4.

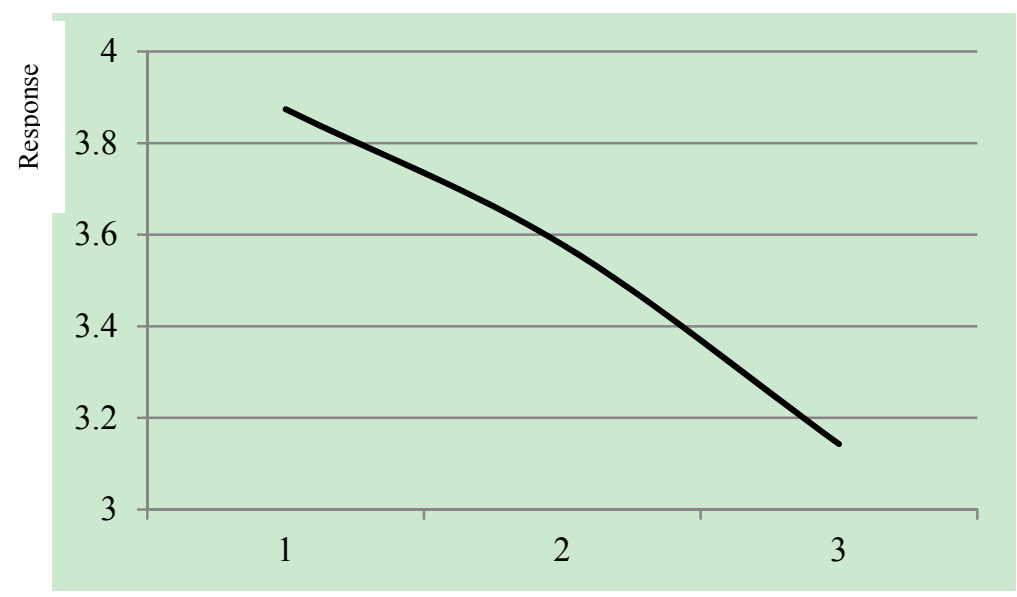

Figure 4. The line graph of means based on the respondents age groups.

Figure 4 shows that the interest for science decreases with age. The next analysis is to see whether the difference of mean between the different age groups is significant or not by using one-way ANOVA. The result of the test is shown in Table 11.

Table 11. The one-way ANOVA test between the means of the respondents

\begin{tabular}{cccccc}
\hline & Sum of Squares & df & Mean Square & F & Sig. \\
\hline Between Groups & 21.169 & 2 & 10.585 & 10.822 & .000 \\
Within Groups & 619.126 & 633 & .978 & & \\
\hline Total & 640.296 & 635 & & & \\
\hline
\end{tabular}

Table 11 shows that the $p$ value is 0.000 and the value is smaller than the critical value of 0.05 . This shows that the mean difference between the respondents of different age group is significant.

\section{Result and Discussion}

There results of the study show that the respondents accepted the statement "I am interested in science". The mean response is 3.7710 (see Table 1). The mean lies between response 3 and response 4 . The value 3.7710 is not strong indicator that they are interested in science. The mean of the response is reflected by the percentages of the responses which show $44.5 \%$ of the respondents agree and $23.8 \%$ strongly agree, and hence cumulatively the percentage of acceptance is $68.3 \%$ (see Table 3). Generally, the Malaysian public shows interest in science but the interest is not strong enough. The analysis which was made on the basis of the ethnics of the respondent also shows that there is no significant different of the interest in science among the different ethnic groups. Analysis of mean base on the ethnic of the respondents shows that there are differences of means of the response between the respondents. However the difference of mean is not significant, indicating that there are no differences to interest in science between the ethnic groups. In addition, in Malaysia, all students are given equal 
opportunity to pursue education in various fields including science and technology. This is a very important factor which leads to similar interest in science between different ethnic groups (Wan, 2008).

The analysis for the mean responses according to the age group indicates that the interest in science declines with age (see Figure 3). The decline of interest in science with age has also been confirmed with other studies on the related issue (Lederman \& Abell, 2014).

Analysis based on the gender of the respondents show that there are no difference on the interest of the respondents to science (see Table 3 and Table 4). This indicates that in the Malaysian contact, there is no significant difference between the male and the female in the interest in science. Moreover, in Malaysia, women education is very advanced in almost all the higher institution of education, the female students are more dominant the male students. From year 1970 to year 2000, female students account half of the total student's intake for primary and secondary level (Arnett, 2007).

\section{References}

Arnett, J. J. (2007). International Encyclopaedia of Adolescence: A-J, index (Vol. 1). New York: Taylor \& Francis.

Bucchi, M. \& Trench, B. (2014). Handbook of Public Communication of Science and Technology. New York: Routledge.

Chorafas, D. N. (2011). Education and Employment in the European Union: The Social Cost if Business. England: Gower Publishing Ltd.

Csermely, P. (2007). Science Education: Models and Networking of Student Research Training Under 21. Hungary: IOS Press.

Haren, F. (2010).The Developing World. Singapore: Interestings Book.

Henriksen, E. (2014). Understanding Student Participation and Choice in Science and Technology Education. Dordrecht: Springer.

Hussain, A., \& Idris, N. (2010). Dimensions of Education. New Delhi: Gyan Publishing House.

Lederman, N. G., \& Abell, S. (2014). Handbook of Research in Science Education (Vol. 2). New York: Routledge.

Mahadevan, P. (2007). Sustainable Growth and Economic Development: A Case Study of Malaysia. United Kingdom, UK: Edward Elgar Publishing.

Oxford Business Group Malaysia. (2011). The Report: Malaysia 2011. Kuala Lumpur: Oxford Business Group.

Pinto, R., \& Couso, D. (2007). Contributions from Science Education Research. The Netherland: Springer Science \& Business Media. http://dx.doi.org/10.1007/978-1-4020-5032-9

Sarji, A. (1993). Malaysia's Vision 2020: Understanding the Concept, Implications and Challenges. Kuala Lumpur: Pelanduk Publication.

Wan, G. (2008). The Education of Diverse Student Populations: A Global Perspective. London: Springer Science \& Business. http://dx.doi.org/10.1007/978-1-4020-8204-7

\section{Copyrights}

Copyright for this article is retained by the author(s), with first publication rights granted to the journal.

This is an open-access article distributed under the terms and conditions of the Creative Commons Attribution license (http://creativecommons.org/licenses/by/3.0/). 